\title{
Bioethanol from corn stover - a review and technical assessment of alternative biotechnologies
}

\author{
Zhao, Yan; Damgaard, Anders; Christensen, Thomas Højlund
}

Published in:

Progress in Energy and Combustion Science

Link to article, DOI:

10.1016/j.pecs.2018.03.004

Publication date:

2018

Document Version

Peer reviewed version

Link back to DTU Orbit

Citation (APA):

Zhao, Y., Damgaard, A., \& Christensen, T. H. (2018). Bioethanol from corn stover - a review and technical assessment of alternative biotechnologies. Progress in Energy and Combustion Science, 67, 275-291. https://doi.org/10.1016/j.pecs.2018.03.004

\section{General rights}

Copyright and moral rights for the publications made accessible in the public portal are retained by the authors and/or other copyright owners and it is a condition of accessing publications that users recognise and abide by the legal requirements associated with these rights.

- Users may download and print one copy of any publication from the public portal for the purpose of private study or research.

- You may not further distribute the material or use it for any profit-making activity or commercial gain

- You may freely distribute the URL identifying the publication in the public portal 
Bioethanol from corn stover - a review and technical assessment of alternative biotechnologies

5

Yan Zhao ${ }^{1}$, Anders Damgaard ${ }^{2}$ and Thomas H. Christensen ${ }^{2, *}$

Kongens Lyngby 2800, Denmark

10

11 First author: Yan Zhao, yanzhao@bnu.edu.cn

12 Corresponding author: Thomas H. Christensen, thho@,env.dtu.dk

14 Running title: Review on bioethanol from corn stover 


\section{Abstract}

2 Reviewing the literature from the last decade regarding the bioconversion of corn stover into ethanol, 474 3 references were identified containing 561 datasets. We found 144 datasets which were sufficiently

4 consistent and detailed to address the current state of the art of corn stover conversion to bioethanol, and 5 we were able to categorise $93 \%$ of these datasets into eight different technological configurations for the 6 production of bioethanol, based on the pretreatment approaches used. After pretreating, the corn stover is 7 subject to hydrolysis and fermentation, but these two process steps were largely identical in all datasets, 8 albeit a range of operating conditions was reported. The final distillation of the ethanol was very rarely 9 included in the datasets. By parameterising the bioethanol production by 26 parameters, including corn 10 stover compositions, solid loadings, operational conditions, conversion efficiencies and material 11 consumption, we were able to quantify the material flows for each technological configuration and estimate 12 the uncertainty of the flows. The eight technological configurations produced $11-22 \%$ ethanol from the dry 13 solid content of the corn stover. Technologies using alkaline-, solvent or ammonia-based pretreatments 14 produced the largest amount of ethanol (19-22\%), while fungi-based pretreatment produced much less 15 (11\%). All technological configurations resulted in large flows of solid as well as liquid residues, typically 16 containing 60 to $70 \%$ of the dry solid corn stover content. Based on the selected datasets, statistical 17 description is provided for all parameters, including mode, median, average and deviation, within each 18 technological configuration. Bivariate correlation analysis across and within all technological 19 configurations indicates that some operational parameters usually considered crucial in laboratory studies, 20 e.g. pretreatment severity, show from a statistical perspective very little correlation with the yields. The 21 review reveals that a great deal of research has addressed the challenge of converting corn stover into 22 bioethanol, but a significant part of these studies is of limited value in terms of scope and documentation 23 when addressing overall material flows and key parameters in a technological context.

\section{Keywords}

26 Bioethanol; corn stover; review; technology; pretreatment; material flow analysis

Abbreviations: PT, pretreatment; HL, hydrolysis; FT, fermentation; PS, pretreatment severity; SL, solid loading; TS, total solid. 


\section{Contents}

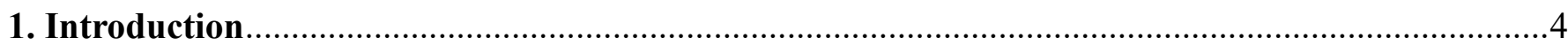

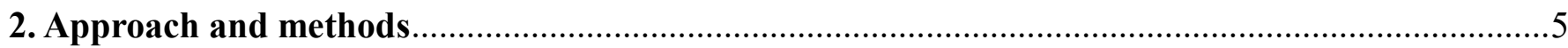

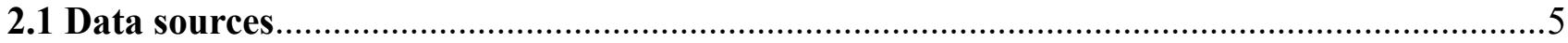

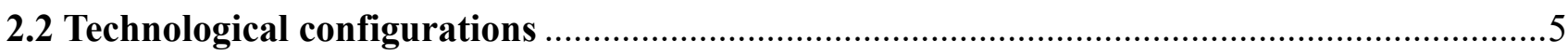

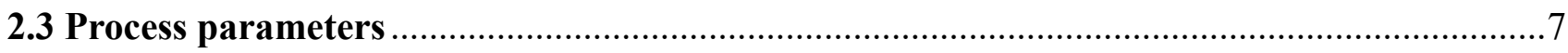

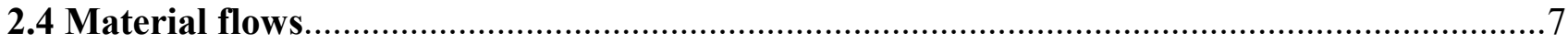

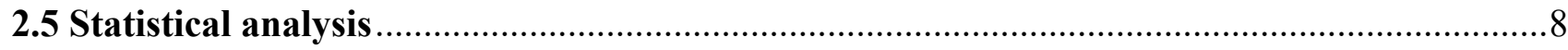

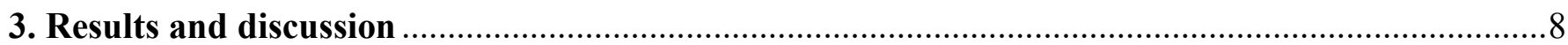

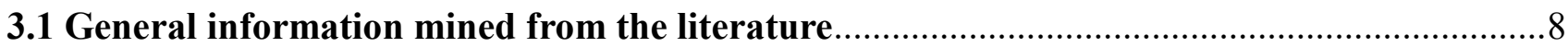

3.2 Material flows in eight technological configurations..........................................................

3.3 Corn stover composition and ethanol yields ………………………………………….....10

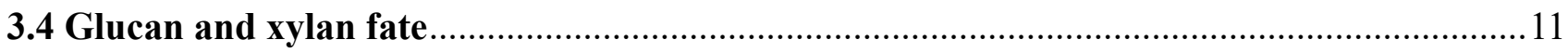

3.5 Process parameters …………………………………………………………………12

3.6 Statistical parameter assessment ..................................................................................13

3.6.1 Best-pratice within a technologucal configuration .......................................................14

3.6.2 Pretreatment and hydrolysis across technological configurations ..............................14

3.6.3 Pretreatment and hydrolysis within each technological configuration .......................15

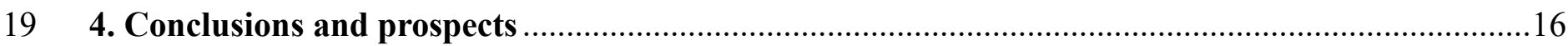

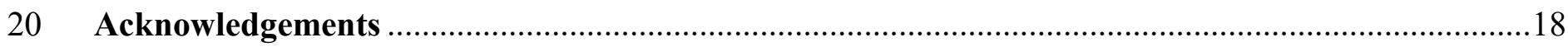

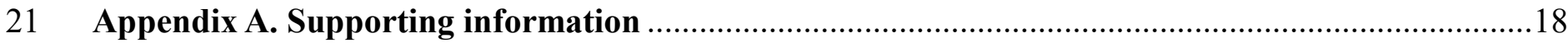

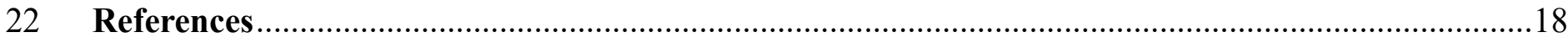

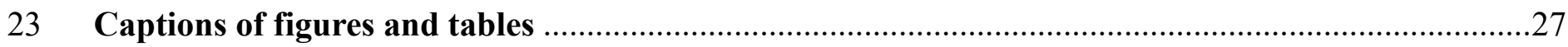




\section{Introduction}

The introduction of biofuels into the transport sector is considered an important and necessary contribution to reducing the dependence of modern society on fossil energy, and bioethanol has already been introduced as an alternative to gasoline in some countries (e.g. USA, Brazil and India) [1-3]. From a sustainability point of view, bioethanol should be produced from secondary biomass deriving mainly from lignocellulosic waste, with the advantages of both utilising the waste through resource recovery and avoiding using biomass that would otherwise be useful as food for human [4]. Significant quantities of lignocellulosic waste are available widely throughout the world; in particular corn stover $[2,5]$. Corn is not only the largest agricultural commodity in the world $\left(1.06 \times 10^{9} \mathrm{t} / \mathrm{y}\right.$ of corn, $7.49 \times 10^{8} \mathrm{t} / \mathrm{y}$ of wheat and $7.41 \times 10^{8} \mathrm{t} / \mathrm{y}$ of rice) [6], but the by-product part of corn in terms of the stover is also significant. Therefore, bioethanol production from corn stover could be an important technology for producing ethanol as a gasoline substitute.

As a typical lignocellulosic feedstock, corn stover contains lignin, cellulose and hemicellulose, collectively constituting a complex polymer structure which restricts reaction media or enzymes to get in close contact with cellulose; thus corn stover is not easily converted into bioethanol [7]. This makes pretreatment which aims toward breaking down the crystalline and polymeric structures an important step prior to the hydrolysis, fermentation and final purification stages. While the latter steps are technologically relatively well known, a lot of research has been carried out recently on the pretreatment of corn stover, including physical, chemical, biological and other processes [8, 9]. Typically, physical pretreatment involves milling, extrusion, and microwave irradiation; physicochemical pretreatment refers to steam explosion, liquid hot water, ammonia fiber explosion and supercritical $\mathrm{CO}_{2}$ explosion; chemical pretreatment usually applies acid and alkaline substances, and sometimes organic solvent or ionic liquid as reaction media; while biological pretreatment employs microorganisms like different types of fungi [10]. Enzymatic hydrolysis is the dominated process for hydrolyzing the carbohydrates, though acid and hydrothermal technologies can also serve as hydrolysis processes. These technologies aim at the same target of maximising ethanol production, but they have essential differences in terms of their approach, operational parameters and yields, and even within the same technology, the operational conditions as well as sugar and ethanol yields vary greatly. Furthermore, full-scale technologies are still in short supply and in the early stages of development $[10,11]$, and there is no clear picture of which pretreatment processes and overall technological configurations are most efficient in producing bioethanol from corn stover. 
To address the current state of the art of different approaches for corn stover conversion to bioethanol,

2 a literature review was conducted on bioconversion processes, focusing on a technological perspective from nearly 500 papers published over the last 10 years. This was achieved by using material flow analysis and

4 statistically assessing all of the relevant parameters identified in the study. From each dataset we extracted 5 data and generated statistical distributions on key parameters for operational conditions and component yields within all the technological configurations including pretreatment, hydrolysis and fermentation.

7 These also form the basis for the mass flow analysis for each technological configuration. The results from 8 material flow and statistical analysis can provide comprehensive and undiscovered information across the 9 individual studies and the technologies. This can serve for potential improvement of bioethanol production 10 from corn stover regarding the choice of relevant technologies and operational parameters. The review also 11 identified the most promising technological approach to produce bioethanol from corn stover and identified 12 where further research and development are needed.

\section{2. Approach and methods}

\section{$15 \quad 2.1$ Data sources}

Given the scarce information of industrial practices, only academic publications were included in this review for consistent, transparent and scientific purposes. Web of Science ${ }^{\mathrm{TM}}$ was searched for the last 10 papers, as shown in Section A1.1 of Supporting Information.

The 474 papers contained 561 datasets, which we evaluated on the basis of their completeness and consistency, as described in Section A1.2 of Supporting Information. The focus and quality of data in the papers varied significantly, but 144 datasets from 120 papers (see references of [13-132]) with relatively high completeness and/or consistency were selected and subjected to further analysis. In addition, the basic information for all 561 datasets is listed in Section A1.3 of Supporting Information, including author and publication information, process classification and scale information and the basic values of glucan, glucose 27 and ethanol yields, where available.

\subsection{Technological configurations}

For the data analysis, we grouped 141 out of the 144 datasets into eight technological configurations according to pretreatment characteristics [12]. This is because the pretreatment process is a significant and 
1 the most studied step in the bioconversion of corn stover to ethanol. The pretreatment strongly affects the

2 availability of substrates for the enzymatic hydrolysis and the quantity and composition of what is input

3 into the fermentation process. In most of the reported studies, the fermentation step and the final distillation

4 (if included in the dataset) were almost identical. A technological configuration is a combination of

5 processes that addresses all steps required in pretreating and converting corn stover to ethanol, namely pretreatment, hydrolysis, fermentation and distillation. Within each technological configuration, variations appear, for example in retention time, temperature and the usage of chemicals and enzyme, and thus also in conversion efficiencies. The eight technological configurations are described below. The remaining three datasets out of the 144 applied emerging solvent-based pretreatment and chemical hydrolysis [13-15], which were not included in this study for statistical reasons, although they did show high completeness 11 and/or consistency (see Table A11, Section A1.3 in Supporting Information). We also identified research 12 using radiation and electrochemistry in the pretreatment process as well as hydrothermal and 13 bioelectrochemical hydrolysis, but these datasets were few in number and uncertain and/or did not provide 14 the consistency needed for identification as a full process configuration (see Table A12, Section A1.3 in 15 Supporting Information). A detailed description of these technological configurations is available in Section occasionally hydrochloric acid and organic acid pretreatment. Pretreated corn stover is subjected to pretreatment, occasionally calcium hydroxide and calcium carbonate pretreatment. Pretreated corn stover A2.1 of Supporting Information.

The eight technological configurations are defined briefly as follows, while the reference numbers involved in each configuration can be found in Section A1.3 of Supporting Information.

- S1-Acid (27 datasets from references [16-40]): Primarily dilute sulphuric acid pretreatment, enzymatic hydrolysis and then fermentation after washing with water.

- S2-Alkaline (19 datasets from references [30, 38, 41-56]): Primarily sodium hydroxide is subjected to enzymatic hydrolysis and then fermentation after washing with water.

- S3-Solvent-based (14 datasets from references [17, 21, 22, 24, 29, 57-65]): Ionic liquid (IL) and/or organic solvent (OS) pretreatment. Pretreated corn stover is subjected to enzymatic hydrolysis and then fermentation after solvent separation and washing with water, or sometimes without washing.

29 catalyst, and in one case acid is used as a catalyst. Pretreated corn stover is subjected to enzymatic hydrolysis and then fermentation after washing with water. 
- S5-Liquid hot water (11 datasets from references [35, 58, 83-91]): Compressed hot water or hydrothermal pretreatment without a catalyst. Pretreated corn stover is subjected to enzymatic hydrolysis and then fermentation after washing with water.

- S6-Ammonia-based (27 datasets from references [22, 24, 29, 38, 39, 64, 92-109]): Primarily ammonia fibre expansion (AFEX), occasionally low moisture anhydrous ammonia (LMAA) and ammonia recycle percolation (ARP) pretreatment. Pretreated corn stover is subjected to enzymatic hydrolysis and then fermentation after ammonia removal, or sometimes washing with water.

- S7-Fungi (11 datasets from references [53, 110-119]): Various fungi species are used for pretreatment. Pretreated corn stover is subjected to enzymatic hydrolysis and then fermentation directly with two cases of washing with water.

- S8-Combi (15 datasets from references [97, 98, 120-132]): Various combinations of physical, chemical and thermochemical pretreatment. Pretreated corn stover is subjected to enzymatic hydrolysis and then fermentation after washing with water.

\subsection{Process parameters}

The selected datasets were not complete seen from a technological point of view, probably due to their different purposes and the research focus, and so this made any direct comparison of the results impossible. Therefore, we defined parameters able to describe all processes in the technological configurations, thereby making it possible to obtain systematic quantitative information from the datasets both across and within technological configurations. The material flows, carbon flows and ethanol yields were calculated based on the parameters identified in Table 1. Data on corn stover composition, solid loading, operational conditions, conversion efficiencies (yields in each process), material consumption, and generated ethanol are reported data or calculated from reported data, following which they are treated as independent parameters, except for pretreatment severity (PS) and some of the raw materials data (e.g. OPP_RM), which were derived from other basic data and are thus dependent.

\subsection{Material flows}

Based on the parameters in Table 1, compiled for each of the 141 datasets considered consistent, material flows as dry solids and as carbon were estimated for each of the eight technological configurations with the EASETECH (version 2.5.3) material flow and LCA model [133] and presented by using the statistical substance flow model STAN (version 2.6.8) [134]. The many datasets available for each technological configuration allowed for quantifying any uncertainty in material flows while maintaining 
1 the overall mass balance, including the flows of components, carbon, ethanol, fermentation gas, solid

2 residue and liquid residue. Some datasets did not contain enough information to obtain all relevant

3 parameters for material flows, and so these datasets were supplemented with median values from existing

4 data on the same parameter and in the same technological configuration.

\section{$5 \quad 2.5$ Statistical analysis}

For the selected 141 datasets, statistical analysis was performed to investigate parameter distribution and correlation. The statistical description, including the average, deviation, mode and distribution of each parameter in each process configuration, was calculated with the statistical software MiniTab 17.1. The correlation analysis of key parameters was performed with the statistical software IBM SPSS 20.0. Specifically, the bivariate correlation analysis applied a Spearman correlation coefficient with a two-tailed 11 test of significance in the confidence levels of $95 \%$ and $99 \%$.

\section{Results and discussion} \\ 3.1 General information mined from the literature}

The time-wise distribution of the 474 papers (2007-2016), on the bioconversion of corn stover to ethanol, showed an increase from 2007 to 2011 followed by a levelling off at around 60 annual publications (Figure 1). datasets), ammonia-based pretreatment (S6, 75 datasets) and alkaline pretreatment (S2, 62 datasets). Figure

The pretreatment covered 11 different approaches, but four of them covered about two-thirds of all datasets in the publications: acid pretreatment (S1, 143 datasets), steam explosion pretreatment (S4, 92 2 shows that pretreatment with acid and with steam explosion dominated 10 years ago, but have dropped in recent years. In contrast, solvent-based and combi pretreatments receive increasing attention.

Hydrolysis was for more than $95 \%$ of the publications enhanced by the use of enzymes. Cellulase (such as Cellic ${ }^{\mathrm{TM}} \mathrm{Ctec} 2$ or $\mathrm{Ctec} 3$ from Novozyme) was used in all the studies as a single enzyme or in an enzyme cocktail, sometimes with glucosidase or xylanase as supplements.

Fermentation to ethanol, which was included in approximately half of the studies, was rather conventional, using mainly yeast (92\%) and sometimes bacteria (8\%), and needs no further description in this context. Purification was often not described in the research, but it would typically involve distillation, which is a well-known technology with relatively stable and high effectiveness.

The 474 publications contained in total 561 sets of data, with $98 \%$ from laboratory-scale studies and 
1 only 11 datasets from pilot-scale experiments. Only one study addressed a techno-economic assessment for

2 a full-scale technology [57], which suggests that experimental data on corn stover conversion to bioethanol

3 are still in the early stage. The majority of the datasets focused on the pretreatment technology, and fewer

4 than $20 \%$ reported on the full combination of pretreatment, hydrolysis and fermentation. Very few datasets

5 included the final distillation of the bioethanol.

Mass balances are crucial for quantifying material flows and for assessing the overall technology, but only 68 out of 561 datasets included mass balances to a different extent. We noted in the literature survey that those publications with mass balances in general garnered more citations than those without mass balances, details of which can be found in Section A3.2 of Supporting Information.

\subsection{Material flows in eight technological configurations}

Figure 3 presents the material flows for the technological configurations S1-S8, which represent 100 units of dry matter in mass and account for five material fractions: glucan (representing cellulose), xylan

13 (representing hemicellulose), lignin, ash and "others". In cases where information about the composition 14 was incomplete, "others" was introduced to account for different approaches used in characterisation and 15 in order to balance consistently the flows to 100 units. Table 2 summarises the major outputs of the material 16 flow analysis, and more details about the material flows can be found in Section A4.1 of Supporting Information. Outputs can exceed $100 \%$ of corn stover solids, due to the uptake of water during hydrolysis. technologies as well as within technologies. Ethanol production was between $11-22 \%$ of total solids in corn stover. In broad terms, the relative standard deviation of ethanol output was around $20-25 \%$ within a technology, with those using alkaline, solvents and ammonia in pretreatment (S2, S3 and S6) showing the highest output of ethanol (19-22\%), while pretreatment with fungi (S7) resulted in the lowest ethanol output $(11 \%)$. of the lignocellulose.

All technologies generated large flows of residues, typically of the order 60 to $70 \%$ of the input mass. Acid pretreatment (S1) seemed to generate slightly higher amounts of residue, while pretreatment with ammonia (S6) or fungi (S7) generated slightly fewer residues. The distribution between solid and liquid 
1 residues varied between technologies, but typically, the liquid residue, which consisted of dissolved

2 components, generated in and washed out after pretreatment, constituted the majority. The fungi-based 3 technology (S7) was an exception, with nearly twice as much solid as liquid residue.

In terms of the carbon content of the corn stover, the overall picture is that approximately $15-25 \%$ of the carbon becomes ethanol and $8-12 \%$ becomes $\mathrm{CO}_{2}$, released as off-gases from ethanol fermentation. A significant proportion of $\mathrm{C}$ was found remaining in the residues, with typically $16-36 \%$ in the solid and 20 $50 \%$ in the liquid residue (details and diagrams of carbon flows can be found in Section A4.2 of Supporting 8 Information).

\section{9}

\subsection{Corn stover composition and ethanol yields}

The composition of the corn stover used in the research and reported in 133 datasets showed a number of variations - averages and standard deviations were: $36.2 \% \pm 3.2 \%$ of cellulose (as glucan), $22.7 \% \pm 4.2 \%$ of hemicellulose (as xylan), $18.5 \% \pm 3.7 \%$ of lignin, $5.0 \% \pm 2.7 \%$ of ash and $18.3 \% \pm 7.9 \%$ of others. Figure 3 shows that the average corn stover composition was not exactly the same between the technological configurations, but statistical tests based on the glucan content suggest on a $95 \%$ confidence level that only the corn stover used in alkaline pretreatment (S2) had an average glucan content slightly higher than the average of all 133 datasets reporting on the glucan content: 2\% more glucan on a dry basis or, relatively, $5.5 \%$ more glucan than the average corn stover. This may contribute potentially to the observed high (second highest) bioethanol yield of this technological configuration, but it will not change the fact that it is one of the top technologies from the view of ethanol production. Comparisons between any two specific technological configurations, however, showed that glucan content was not identical in the combinations S2 versus S6, S4 versus S7 and S6 versus S7 (see Section A5.1 in Supporting Information).

Theoretically, the average composition of corn stover in terms of glucan (36.2\%) and xylan (22.7\%) could yield, if all processes of pretreatment, hydrolysis and fermentation were $100 \%$ efficient, ethanol corresponding to $20.6 \%$ and $13.1 \%$, respectively, i.e. a maximum ethanol yield by mass of $33.9 \%$ of the dry solids in the corn stover.

Overall, ethanol yield from the raw glucan content of the corn stover typically varied in the range 35$85 \%$, as illustrated in Figure 4a. The ammonium-based technological configuration (S6) showed values in the interval of $75-90 \%$, while the fungi-based technological configuration (S7) showed values in the interval of $35-50 \%$. The other technological configurations also varied in their ethanol yields relative to glucan content, but they were all located around the value of $70 \%$ - as also reported by the USA National 
1 Renewable Energy Laboratory [28]. Relating ethanol yield to the sum of glucan and xylan in the corn stover

2 did not change the picture (Figure 4b), except that the average yields decreased significantly (note that only

3 a few datasets allow for including both glucan and xylan).

$4 \quad 3.4$ Glucan and xylan fate

Glucose and xylose are considered the main substrates for the fermentative production of ethanol. The ability of the technological configuration to convert solid glucan and xylan to glucose and xylose, respectively, and to route these dissolved compounds to the fermentaion step, is the key factor in obtaining high yields of ethanol. In most published research, the focus has fallen on glucan, which is the major substrate component, and routing the derived glucose to fermentation, where yeast converts glucose to ethanol. In many cases, little attention has been paid to xylan and xylose, which chemically in terms of 11 composition and in terms of conversion differ significantly from glucan and glucose. The hydrolysis of 12 xylan to xylose, and the fermenation of xylose to ethanol, is typically done by different enzymes (xylanase 13 such as Cellic ${ }^{\mathrm{TM}} \mathrm{Htec} 2$ and Htec3 from Novozyme) and different organisms (such as ethanolic E. coli) [41, 14 135-137] than the cellulase/glucanase used in converting glucan to glucose and the yeast employed to 15 convert glucose to ethanol.

Figure 5 illustrates the fate of glucan and xylan in the technological configurations, all the way through to ethanol. Where data were not provided directly by the references, we calculated the fate from reported 18 data on component concentrations and balanced these against the ethanol data, where possible. We 19 neglected microbial growth in these calculations. Data in pretreatment and hydrolysis are available in $70 \% \sim 90 \%$ of the 141 datasets. However, fermentation possesses only 61 and 28 avaliable data for ethanol 21 yields from glucose and xylose, respectively, and the missing data were not included in the statistcial data.

The pretreatment step opens and partly dissolves the fibre structure of corn stover, and in most cases

24 (S1) seems often to lose both glucan and xylan to the liquid residue, and steam-explosions (S4) as well as liquid hot water (S5) lose a significant part of the xylan. Alkaline (S2) and ammonia-based (S6) pretreatments lose the least amount of xylan in this regard. It should be noted that the variation is large within each technological configuration, thereby suggesting that most of the glucan and xylan, if proper attention is paid, can be kept in the solid fraction transferred to hydrolysis.

The hydrolysis step converts glucan and xylan into dissolved glucose and xylose, respectively, and the liquid fraction is transferred to fermentation. Figure 5 shows that in general all technological configurations 
are better at transferring glucose than xylose to the liquid flow routed to fermentation. Conversion of glucan to glucose is particularly high for the solvent-based pretreatement (S3), while acid-based pretreatment (S1) often shows lower glucan as well as xylan conversion efficiencies. In addition, in the hydrolysis step, we observe large variations within each technological configuration.

The data on fermentation are less substantial. Nearly all reported experiments observed between an $80-100 \%$ conversion of glucose to ethanol, and the type of microorganism (yeast or bacteria) had no statistically significant influence on the ethanol yield. In contrast, large variations were observed for the conversion of xylose, also within a single technological configuration. However, it should be noted that several references reported the high conversion of xylose to ethanol. In contrast, in S7, only a few datasets included fermentation and showed low values, resulting in low average ethanol yields, which potentially contributes to the relatively lower ethanol production and high amounts of residues discussed in Sections 3.2 and 3.3 .

Figure 5 illustrates that the actual performance of a technological configuration varied signifcantly in relation to its ability to convert solid glucan and xylan to ethanol, which suggests that a great deal can be obtained by optimising each individual process in the technological configurations. However, it also suggests that some approaches in the pretreatment and hydrolysis stages tend to perform better and may potentially be easier to optimise, as shown by the glucose yields after pretreatment and hydrolysis in Figure A4, Section A5.2 in Supporting Information.

\subsection{Process parameters}

The differences in ethanol production between technological configurations, as well as variations within a technological configuration, may be caused to some extent by differences in operational parameters such as temperature, retention time, solid loading, etc. Figure 6 presents the distribution of nine key operational parameters according to technological configurations. The distribution of additional operational parameters in each technological configuration is included in Figure A3, Section A5.2 in Supporting Information. Due to the focus of the published research, most data are available for pretreatment and the hydrolysis but much less so for fermentation.

Solid loading (\%TS) in the pretreatment varied highly between technological configurations, ranking from very dilute systems with only less than 5\% TS to close to dry systems, with the latter mainly applied in technological configurations with solvent (S3) and steam explosion (S4) pretreatments, but as shown in Figure 6, large variations were also found within the single technological configuration. Fewer differences 
and variations were apparent in hydrolysis and fermentation.

Pretreatment retention time varied typically between a few minutes to a few hours, with fungi pretreatment having a much longer retention time of the order of one to several weeks. The retention times

4 for hydrolysis and fermentation were typically a day to a week, with 48 to $72 \mathrm{~h}$ as the most frequent values 5 (details in Table 3).

The pretreatment temperature usually increased to reach $120-180^{\circ} \mathrm{C}$ in the different technological configurations, except for the fungi pretreatment, and in some cases of pretreatment with steam explosion and liquid hot water the temperature reached $200^{\circ} \mathrm{C}$ or even higher (Figure 6). In specific cases, a higher temperature was used, but this was often linked to shorter retention times, thereby suggesting that pretreatment severity did not deviate very much (see Section A5.2 of Supporting Information). This phenomenon is explained further in Section 3.6 from a statistical perspective. The hydrolysis step is often at a moderate temperature $\left(50^{\circ} \mathrm{C}\right)$ and fermentation at a mesophilic temperature $\left(37^{\circ} \mathrm{C}\right)$.

Pretreatment with hot water (S5) or fungi (S7) demanded no use of chemicals, while the dosage of chemicals in the other pretreatments varied dramatically, often between 5-20\% of the TS in the corn stover. An exception was the solvent-based pretreatment (S3), where dosages could exceed $5 \mathrm{~kg}$ solvent per $\mathrm{kg}$ of TS. It was expected that a significant fraction $(>95 \%)$ of ammonia as well as solvents used in the pretreatment could be recovered and reused in the technological configurations of S6 and S3, respectively, although this aspect often was not addressed in laboratory studies. The dosage of enzymes in the hydrolysis step also varied significantly, typically between 10 to $100 \mathrm{~g}$ per $\mathrm{kg}$ of TS fed into the hydrolysis stage. Details on enzyme dosage calculation are available in Section A2.2 in Supporting Information.

Datasets representing pilot-scale studies were not significantly different from those covering laboratory-scale studies, except with respect to the use of chemicals. Data from three pilot-scale studies [28, 44,93 ] used two to five times fewer chemicals per kg TS than averages for corresponding technological configurations reported in the laboratory scale (S1-Acid, S2-Alkaline and S6-Ammonia-based, respectively).

\subsection{Statistical parameter assessment}

On the basis of all available data in each technological configuration, statistical descriptions of the parameter distributions, including mode, median, average and deviation, for all operational parameters are presented in Table 3. This information reveals the most commonly used conditions in every process within each technological configuration, so that we can better understand the difference introduced by the intrinsic 
1 property and parameter variation of the configurations. The statistical information for all the yields can be

2 found in Section A5.3 in Supporting Information.

\subsubsection{Best-pratice within a technologucal configuration}

Based on the parameter statistics, we can define a probable "best-practice" using the top $15 \%$ of the yields in each individual process, and we can also estimate the expected ethanol production of the technological configuration as described in Section A6.1 of Supporting Information. The results are shown in Table 4 in terms of "best" efficiencies of each process step as well as the ethanol yields from glucan and xylan. The technological configuration with ammonia-based pretreatment (S6) shows a potential ethanol production of $30.6 \%$ of the total solid in corn stover, followed by S2 (27.0\%), S8 (26.5\%), and S3 (26.3\%) (see Table 4). The conversion of glucan to ethanol is "best-practice" in the range $88 \%$ to $93 \%$ of the maximum potential except for the technological configuration using fungi in pretreatment. Table 4 also shows that the bioconversion of xylan to ethanol varies much more (25-85\%) in the "best-practice" technologies, suggesting that high xylan conversion efficiency is crucial to overall ethanol production.

Compared with the ethanol production obtained from material flow analysis (Figure 3), the "bestpractice" is supposed to produce approximately $30 \% \sim 50 \%$ more ethanol within each technological configuration. This indicates that most of the studies did not succeed in optimizing the entire configuration for bioethanol production, given their focuses on specific processes. Therefore, technological optimization must be considered from a systematic perspective in the future, to maximize the ethanol production capacity from corn stover.

\subsubsection{Pretreatment and hydrolysis across technological configurations}

In addition to the observation that the fate of glucan and xylan in pretreatment and hydrolysis is crucial to overall ethanol production, some experimental studies [37, 138-143] have also considered as important parameters such as lignin content, pretreatment severity and solid loading to overall ethanol production. To assess the general validity of these observations, we conducted bivariate correlation analyses on all 141 datasets across all technological configurations with respect to compositions and yields of glucan/glucose, xylan/xylose and lignin in pretreatment and hydrolysis. The results are shown in Table 5.

We observed a strong correlation between the yield of glucan/glucose and xylan/xylose in both pretreatment and hydrolysis, in that when one was high, the other was likely to be high as well. Lignin content in the raw corn stover was negatively correlated with the yields of both glucose and xylose in hydrolysis at a 99\% confidence level, suggesting that a high content of lignin in corn stover does indeed 
1 make it more difficult for enzymatic hydrolysis to make the sugars available for fermentation into ethanol.

2 In contrast, no significant correlation was observed between xylan content in raw materials and any yield

3 in pretreatment or hydrolysis. Furthermore, the yields of xylan and lignin in pretreatment did not show a

4 strong correlation with the yields of glucose and xylose in the subsequent hydrolysis. From this point of

5 view, the existence of lignin is very likely adverse to sugar yields in hydrolysis, but xylan routed to

6 hydrolysis does not necessarily affect the success of hydrolysis, as observed otherwise in some laboratory 7 studies.

8 Pretreatment severity calculated as a combination of temperature and retention time (see Section A2.2 9 in Supporting Information) has commonly been used in the literature for explaining varying sugar yields $10[66,86,142,144]$. According to the correlations observed in Table 5, across all datasets pretreatment 11 severity has little correlation with yields in general, except for the xylan yield in pretreatment. This suggests 12 that the more severe the pretreatment, the more xylan/xylose is lost to the liquid reject flow removed at the 13 end of pretreatment by washing. Since xylose fermentation into ethanol is an important part of the overall 14 ethanol production process, as shown in Table 4, each technological configuration should balance 15 pretreatment severity against the undesirable loss of xylan/xylose. Table 5 also reveals a weak but 16 statistically positive correlation between pretreatment severity and the proportion of lignin remaining after 17 pretreatment in the solid flow being routed to hydrolysis. We do not consider this an observation of general 18 validity, though, because it originates from the fact that the technological configurations S4 (steam 19 explosion pretreatment) and S5 (liquid hot water pretreatment) are specifically efficient in keeping lignin 20 in the solid fraction, although the severity of the pretreatment is high. These two technological 21 configurations use only water and steam in pretreatment, and thus they require higher temperatures and/or 22 longer retention times (Figures A3e and A3f, Section A5.2 in Supporting Information).

\section{$23 \quad 3.6 .3$ Pretreatment and hydrolysis within each technological configuration}

Bivariate correlation analysis was also performed within each of the seven technological configurations for the fate of glucan and xylan against operational parameters, including solid loading, temperature, retention time, dosage of chemicals and enzymes as well as pretreatment severity. Supporting Information (Section A6.2) contains correlation coefficients and their level of significance for the bivariate analysis.

The overall outcome of the correlation analysis is that a single, dominant parameter, or a few dominant operational parameters, cannot be identified within the single technological configuration. Significant 
1 statistical correlations with high correlation coefficients $(\geq 0.4)$ were identified in some cases (16 out of

2 169), but although a likely explanation could be hypothesised for one correlation, we could not find 3 consistent explanations across all correlations identified within a technological configuration. More

4 specifically, seven out of the 16 significant correlations related to solid loading (five from pretreatment and 5 two from hydrolysis), and four out of the 16 related to chemical dosage and four to reaction time (three 6 from pretreatment and one from hydrolysis). No significant correlation was observed between pretreatment 7 severity and any yield of glucan/glucose and xylan/xylose, thereby suggesting that pretreatment severity 8 does not necessarily correlate to the yields as expected.

In general, the statistical results might suggest that the effect of combined pretreatment and hydrolysis, 10 which determines how much glucose and xylose are routed to the ethanol fermentation reactor, is influenced 11 by many factors and, perhaps, interacting factors. However, after pretreatment, glucan/glucose and 12 xylan/xylose should stay in the solid flow routed to hydrolysis, while after hydrolysis, glucose and xylose 13 should be fully dissolved and transferred to the liquid flow routed to the ethanol fermentation reactor. Hence, 14 future studies should pay more attention to the control of the solid-to-liquid ratio and the amount of washing 15 water, as well as the separation processes applied. Information about these issues was very scant in existing 16 laboratory studies.

\section{Conclusions and prospects}

Over the last decade, the bioconversion of corn stover into ethanol - intended for the substitution of gasoline - has been subject to intensive research. We found 474 references directly or indirectly addressing

21 the issue, thereby presenting a total of 561 datasets. The vast majority of the reported research was at the 22 laboratory scale (98\%), and none was from actual full-scale plants. Not all datasets were complete, and 23 some were too rudimentary to provide consistent information about bioethanol production from a 24 technological point of view, i.e. how much ethanol can we obtain from corn stover with different technologies, and what are the key operational parameters in each process? We found that 144 datasets were consistent and contained enough detail to contribute to an evaluation of the current state of the art of corn

27 stover conversion to bioethanol. A large range of technological approaches was researched, but we could categorise $93 \%$ of the datasets into eight different technological configurations for ethanol production. The main differences between the technological configurations were found in the pretreatment phase. The ensuing processes of hydrolysis and fermentation into ethanol were largely identical in the eight 
1 technological configurations, although a range of operating conditions was reported. The final distillation was rarely included in the datasets. The priority of the research, to focus on pretreatment and hydrolysis, clearly reflects the notion that the challenge in converting corn stover into bioethanol lies in making as large as possible a fraction of the cellulose and hemicellulose-rich materials available as sugars that are easy to ferment into bioethanol.

Very few datasets provided data on the material flows, but by parameterising them, we were able to quantify the material flows for each technological configuration, including estimates of flow uncertainty. Of the dry solid content of corn stover, the eight technological configurations produced $11-22 \%$ ethanol. Technologies using alkaline, solvent-based or ammonia-based pretreatments saw the highest ethanol production (19-22\%), while the fungi-based pretreatment produced much less ethanol ( 11\%). All technological configurations resulted in large flows of solid as well as liquid residues. Of the carbon in the corn stover, $15-25 \%$ was converted to bioethanol, while the remaining carbon was found in off-gasses and residues. The utilisation of carbon in residues, which is extremely important for the overall energy balance, was barely reported in laboratory studies. The review reveals not only that a lot of research has addressed the challenge of converting corn stover into bioethanol, but also that a significant part of the research is of limited value when addressing overall material flows and indicating how well the employed technology can ensure that sugars in the flow enters the bioethanol fermentation process.

Based on all of the extracted parameters and the statistical distributions established for key operational parameters, we showed that the optimisation of all steps could make all technological configurations produce high amounts of bioethanol. Technologies using fungi for pretreatment will always produce significantly less bioethanol and seem less attractive from a technological point of view. Bivariate correlation analysis across and within all technological configurations revealed that some operational parameters, which often are claimed to control the processes, for example pretreatment severity, generally showed little correlation with yields and bioethanol production. This indicates that a single dominating parameter, or a few dominating operational parameters, can hardly be identified within the technological configurations.

We conclude on the basis on the literature review that bioethanol production from corn stover is still in its early stages and more research is needed; focus should be on:

- Glucan/glucose as well as xylan/xylose: Glucan/glucose is the main component in corn stover for producing bioethanol and most previous research focus on this aspect, but xylan/xylose can also contribute 
1 significantly if not lost in the pretreatment and if efficiently converted in the fermentation process. It is

2 important to respect that according to the statistics derived from the literature review, glucan/glucose and

3 xylan/xylose do not behave the same in the pretreatment and washing process and that some fermentation

4 process, but certainly not all are able to utilize the xylose. The literature does not provide a clear message

5 here but suggests an issue to be addressed in future research.

- Technology: The statistical analysis of the large amount of research data on bioethanol production suggests that there is a large potential for optimizing each technological approach to obtain high ethanol efficiencies, maybe $19-22 \%$ of the corn stover on a dry mass basis. Many technological configurations are

9 feasible, but three technologies so far look most promising (alkaline, solvent- or ammonia-based 10 pretreatment), while one technology (fungi-based pretreatment) seems of less potential, probably because 11 part of the easily degradable sugars are being degraded already in the pretreatment step and not utilized for 12 ethanol in the later fermentation.

13 - Mas flows: Aiming at developing efficient technologies, it is crucial to document all mass flows 14 (total solids, glucan/glucose, xylan/xylose, carbon) from the corm stover to the bioethanol product, 15 including all the side and residue flows. This will document the efficiency in the bioethanol technology and 16 point to importance of also managing the significant side flows and residues.

\section{Acknowledgements}

19 This work was supported financially by the National Natural Science Foundation of China (No. 51578071) 20 and the China Scholar Council (201606045038). The authors would also like to express their sincere 21 gratitude to Master students Yingjie Xu and Shan Liu, School of Environment, Beijing Normal University, 22 and to Dr. Valentina Bisinella and Dr. Davide Tonini, Department of Environmental Engineering, Technical 23 University of Denmark, for their helpful assistance with the literature and figures and advice on the research 24 ideas and approaches, respectively.

\section{Appendix A. Supporting information}

27 Supporting information associated with this article can be found in the online version.

\section{References}

30 [1] Wojtusik M, Zurita M, Villar JC, Ladero M, Garcia-Ochoa F. Influence of fluid dynamic conditions on 
enzymatic hydrolysis of lignocellulosic biomass: Effect of mass transfer rate. Bioresour Technol. 2016;216:28-35.

[2] Morales M, Quintero J, Conejeros R, Aroca G. Life cycle assessment of lignocellulosic bioethanol: Environmental impacts and energy balance. Renew Sust Energ Rev. 2015;42:1349-61.

[3] Soam S, Kapoor M, Kumar R, Borjesson P, Gupta RP, Tuli DK. Global warming potential and energy analysis of second generation ethanol production from rice straw in India. Appl Energy. 2016;184:35364.

[4] Agostinho F, Bertaglia ABB, Almeida C, Giannetti BF. Influence of cellulase enzyme production on the energetic-environmental performance of lignocellulosic ethanol. Ecol Model. 2015;315:46-56.

[5] Zabed H, Sahu JN, Boyce AN, Faruq G. Fuel ethanol production from lignocellulosic biomass: An overview on feedstocks and technological approaches. Renew Sust Energ Rev. 2016;66:751-74.

[6] FAO. Food and Agriculture Organization of the United Nations. http://www.fao.org/faostat/en/. 2016.

[7] Loow YL, Wu TY, Jahim JM, Mohammad AW, Teoh WH. Typical conversion of lignocellulosic biomass into reducing sugars using dilute acid hydrolysis and alkaline pretreatment. Cellulose. 2016;23:1491520.

[8] Kumar R, Tabatabaei M, Karimi K, Horvath IS. Recent updates on lignocellulosic biomass derived ethanol - A review. Biofuel Res J. 2016;3:347-56.

[9] Capolupo L, Faraco V. Green methods of lignocellulose pretreatment for biorefinery development. Appl Microbiol Biotechnol. 2016;100:9451-67.

[10] Aditiya HB, Mahlia TMI, Chong WT, Nur H, Sebayang AH. Second generation bioethanol production: A critical review. Renew Sust Energ Rev. 2016;66:631-53.

[11] Chen HZ, Fu XG. Industrial technologies for bioethanol production from lignocellulosic biomass. Renew Sust Energ Rev. 2016;57:468-78.

[12] Menon V, Rao M. Trends in bioconversion of lignocellulose: Biofuels, platform chemicals \& biorefinery concept. Prog Energy Combust Sci. 2012;38:522-50.

[13] Han J, Luterbacher JS, Alonso DM, Dumesic JA, Maravelias CT. A lignocellulosic ethanol strategy via nonenzymatic sugar production: Process synthesis and analysis. Bioresour Technol. 2015;182:25866.

[14] Luterbacher JS, Rand JM, Alonso DM, Han J, Youngquist JT, Maravelias CT, et al. Nonenzymatic Sugar Production from Biomass Using Biomass-Derived gamma-Valerolactone. Science. 2014;343:277-80.

[15] Binder JB, Raines RT. Fermentable sugars by chemical hydrolysis of biomass. Proc Natl Acad Sci U S A. 2010;107:4516-21.

[16] Li P, Cai D, Luo ZF, Qin PY, Chen CJ, Wang Y, et al. Effect of acid pretreatment on different parts of corn stalk for second generation ethanol production. Bioresour Technol. 2016;206:86-92.

[17] Nguyen TY, Cai CM, Osman O, Kumar R, Wyman CE. CELF pretreatment of corn stover boosts ethanol titers and yields from high solids SSF with low enzyme loadings. Green Chem. 2016;18:15819.

[18] Yu H, Ren JW, Liu L, Zheng ZJ, Zhu JJ, Yong Q, et al. A new magnesium bisulfite pretreatment (MBSP) development for bio-ethanol production from corn stover. Bioresour Technol. 2016;199:188-93.

[19] Liu K, Zhang J, Bao J. Two stage hydrolysis of corn stover at high solids content for mixing power saving and scale-up applications. Bioresour Technol. 2015;196:716-20.

[20] Liu ZL, Cotta MA. Technical Assessment of Cellulosic Ethanol Production Using beta-Glucosidase Producing Yeast Clavispora NRRL Y-50464. BioEnergy Res. 2015;8:1203-11.

[21] Nguyen TY, Cai CM, Kumar R, Wyman CE. Co-solvent Pretreatment Reduces Costly Enzyme 
Requirements for High Sugar and Ethanol Yields from Lignocellulosic Biomass. ChemSusChem. 2015;8:1716-25.

[22] Xue SS, Uppugundla N, Bowman MJ, Cavalier D, Sousa LDC, Dale BE, et al. Sugar loss and enzyme inhibition due to oligosaccharide accumulation during high solids-loading enzymatic hydrolysis. Biotechnol Biofuels. 2015;8:195-208.

[23] Zhang Q, Zhang PF, Pei ZJ, Xu F, Wang DH, Vadlani P. Effects of ultrasonic vibration-assisted pelleting on chemical composition and sugar yield of corn stover and sorghum stalk. Renew Energy. 2015;76:160-6.

[24] Gao XD, Kumar R, Singh S, Simmons BA, Balan V, Dale BE, et al. Comparison of enzymatic reactivity of corn stover solids prepared by dilute acid, AFEX (TM), and ionic liquid pretreatments. Biotechnol Biofuels. 2014;7:71-83.

[25] He YQ, Zhang J, Bao J. Dry dilute acid pretreatment by co-currently feeding of corn stover feedstock and dilute acid solution without impregnation. Bioresour Technol. 2014;158:360-4.

[26] He YQ, Zhang LP, Zhang J, Bao J. Helically agitated mixing in dry dilute acid pretreatment enhances the bioconversion of corn stover into ethanol. Biotechnol Biofuels. 2014;7:1-13.

[27] Tai C, Keshwani D. Impact of Pretreatment with Dilute Sulfuric Acid Under Moderate Temperature on Hydrolysis of Corn Stover with Two Enzyme Systems. Appl Biochem Biotechnol. 2014;172:262839.

[28] Tao L, Schell D, Davis R, Tan E, Elander R, Bratis A. NREL 2012 Achievement of ethanol cost targets: Biochemical ethanol fermentation via dilute-acid pretreatment and enzymatic hydrolysis of corn stover. National Renewable Energy Laboratory; 2014.

[29] Uppugundla N, Sousa LD, Chundawat SPS, Yu XR, Simmons B, Singh S, et al. A comparative study of ethanol production using dilute acid, ionic liquid and AFEX (TM) pretreated corn stover. Biotechnol Biofuels. 2014;7:72-85.

[30] Yu H, Zhang M, Ouyang J, Shen Y. Comparative Study on Four Chemical Pretreatment Methods for an Efficient Saccharification of Corn Stover. Energy Fuels. 2014;28:4282-7.

[31] Yu G, Li B, Liu C, Zhang YD, Wang HS, Mu XD. Fractionation of the main components of corn stover by formic acid and enzymatic saccharification of solid residue. Ind Crop Prod. 2013;50:750-7.

[32] Chen Y, Stevens MA, Zhu YM, Holmes J, Moxley G, Xu H. Reducing acid in dilute acid pretreatment and the impact on enzymatic saccharification. J Ind Microbiol Biotechnol. 2012;39:691-700.

[33] Theerarattananoon K, Xu F, Wilson J, Staggenborg S, McKinney L, Vadlani P, et al. Effects of the pelleting conditions on chemical composition and sugar yield of corn stover, big bluestem, wheat straw, and sorghum stalk pellets. Bioprocess Biosyst Eng. 2012;35:615-23.

[34] Yoo CG, Kuo M, Kim TH. Ethanol and furfural production from corn stover using a hybrid fractionation process with zinc chloride and simultaneous saccharification and fermentation (SSF). Process Biochem. 2012;47:319-26.

[35] Shi J, Pu YQ, Yang B, Ragauskas A, Wyman CE. Comparison of microwaves to fluidized sand baths for heating tubular reactors for hydrothermal and dilute acid batch pretreatment of corn stover. Bioresour Technol. 2011;102:5952-61.

[36] Van Eylen D, van Dongen F, Kabel M, de Bont J. Corn fiber, cobs and stover: Enzyme-aided saccharification and co-fermentation after dilute acid pretreatment. Bioresour Technol. 2011;102:5995-6004.

[37] Qing Q, Yang B, Wyman CE. Impact of surfactants on pretreatment of corn stover. Bioresour Technol. 2010;101:5941-51.

[38] Chen M, Zhao J, Xia LM. Comparison of four different chemical pretreatments of corn stover for 
enhancing enzymatic digestibility. Biomass Bioenerg. 2009;33:1381-5.

[39] Lau MW, Gunawan C, Dale BE. The impacts of pretreatment on the fermentability of pretreated lignocellulosic biomass: a comparative evaluation between ammonia fiber expansion and dilute acid pretreatment. Biotechnol Biofuels. 2009;2:30-40.

[40] Hodge DB, Karim MN, Schell DJ, McMillan JD. Soluble and insoluble solids contributions to highsolids enzymatic hydrolysis of lignocellulose. Bioresour Technol. 2008;99:8940-8.

[41] Kuhn EM, O'Brien MH, Ciesielski PN, Schell DJ. Pilot-Scale Batch Alkaline Pretreatment of Corn Stover. ACS Sustain Chem Eng. 2016;4:944-56.

[42] Liu H, Pang B, Wang HS, Li HM, Lu J, Niu MH. Optimization of Alkaline Sulfite Pretreatment and Comparative Study with Sodium Hydroxide Pretreatment for Improving Enzymatic Digestibility of Corn Stover. J Agric Food Chem. 2015;63:3229-34.

[43] Xu HF, Yu G, Mu XD, Zhang CY, DeRoussel P, Liu C, et al. Effect and characterization of sodium lignosulfonate on alkali pretreatment for enhancing enzymatic saccharification of corn stover. Ind Crop Prod. 2015;76:638-46.

[44] Chen XW, Shekiro J, Pschorn T, Sabourin M, Tao L, Elander R, et al. A highly efficient dilute alkali deacetylation and mechanical (disc) refining process for the conversion of renewable biomass to lower cost sugars. Biotechnol Biofuels. 2014;7:98-108.

[45] Chu QL, Huang Y, Li X, Fan YM, Jin YC, Yu SY, et al. Improved Enzymatic Hydrolysis of Corn Stover by Green Liquor Pretreatment and a Specialized Enzyme Cocktail. BioResources. 2014;9:4489-502.

[46] Chu QL, Li X, Yang DL, Xu Y, Ouyang J, Yu SY, et al. Corn Stover Bioconversion by Green Liquor Pretreatment and a Selected Liquid Fermentation Strategy. BioResources. 2014;9:7681-95.

[47] Karp EM, Donohoe BS, O'Brien MH, Ciesielski PN, Mittal A, Biddy MJ, et al. Alkaline Pretreatment of Corn Stover: Bench-Scale Fractionation and Stream Characterization. ACS Sustain Chem Eng. 2014;2:1481-91.

[48] Peng HD, Luo H, Jin SY, Li HQ, Xu J. Improved bioethanol production from corn stover by alkali pretreatment with a novel pilot-scale continuous microwave irradiation reactor. Biotechnol Bioprocess Eng. 2014;19:493-502.

[49] Zhao XZ, Liang XX, Han SQ, Uryu T, Yoshida T. Successive Saccharification and Fermentation of Cellulosic Agricultural Residues Using a Combination of Cellulase and Recombinant Yeast. Sen-I Gakkaishi. 2014;70:191-6.

[50] Chen Y, Stevens MA, Zhu YM, Holmes J, Xu H. Understanding of alkaline pretreatment parameters for corn stover enzymatic saccharification. Biotechnol Biofuels. 2013;6:8-17.

[51] Guragain YN, Wilson J, Staggenborg S, McKinney L, Wang DH, Vadlani PV. Evaluation of pelleting as a pre-processing step for effective biomass deconstruction and fermentation. Biochem Eng J. 2013;77:198-207.

[52] Banerjee G, Car S, Liu TJ, Williams DL, Meza SL, Walton JD, et al. Scale-up and integration of alkaline hydrogen peroxide pretreatment, enzymatic hydrolysis, and ethanolic fermentation. Biotechnol Bioeng. 2012;109:922-31.

[53] Cui ZF, Shi J, Wan CX, Li YB. Comparison of alkaline- and fungi-assisted wet-storage of corn stover. Bioresour Technol. 2012;109:98-104.

[54] Li Q, Gao Y, Wang HS, Li B, Liu C, Yu G, et al. Comparison of different alkali-based pretreatments of corn stover for improving enzymatic saccharification. Bioresour Technol. 2012;125:193-9.

[55] Zhang XM, Xu JL, Cheng JJ. Pretreatment of Corn Stover for Sugar Production with Combined Alkaline Reagents. Energy Fuels. 2011;25:4796-802. 
[56] Rodgers M, Hu ZH, Zhan XM. Enhancing Enzymatic Hydrolysis of Maize Stover by Bayer Process Sand Pretreatment. Energy Fuels. 2009;23:2284-9.

[57] Baral NR, Shah A. Techno-economic analysis of cellulose dissolving ionic liquid pretreatment of lignocellulosic biomass for fermentable sugars production. Biofuels Bioprod Biorefining. 2016;10:7088.

[58] Papa G, Rodriguez S, George A, Schievano A, Orzi V, Sale KL, et al. Comparison of different pretreatments for the production of bioethanol and biomethane from corn stover and switchgrass. Bioresour Technol. 2015;183:101-10.

[59] Qin L, Li WC, Zhu JQ, Liang JN, Li BZ, Yuan YJ. Ethylenediamine pretreatment changes cellulose allomorph and lignin structure of lignocellulose at ambient pressure. Biotechnol Biofuels. 2015;8:17488.

[60] Katahira R, Mittal A, McKinney K, Ciesielski PN, Donohoe BS, Black SK, et al. Evaluation of Clean Fractionation Pretreatment for the Production of Renewable Fuels and Chemicals from Corn Stover. ACS Sustain Chem Eng. 2014;2:1364-76.

[61] Resch MG, Donohoe BS, Ciesielski PN, Nill JE, Magnusson L, Himmel ME, et al. Clean Fractionation Pretreatment Reduces Enzyme Loadings for Biomass Saccharification and Reveals the Mechanism of Free and Cellulosomal Enzyme Synergy. ACS Sustain Chem Eng. 2014;2:1377-87.

[62] Xu F, Shi YC, Wang DH. Enhanced production of glucose and xylose with partial dissolution of corn stover in ionic liquid, 1-Ethyl-3-methylimidazolium acetate. Bioresour Technol. 2012;114:720-4.

[63] Dibble DC, Li CL, Sun L, George A, Cheng ARL, Cetinkol OP, et al. A facile method for the recovery of ionic liquid and lignin from biomass pretreatment. Green Chem. 2011;13:3255-64.

[64] Li CL, Cheng G, Balan V, Kent MS, Ong M, Chundawat SPS, et al. Influence of physico-chemical changes on enzymatic digestibility of ionic liquid and AFEX pretreated corn stover. Bioresour Technol. 2011;102:6928-36.

[65] Zhang YHP, Ding SY, Mielenz JR, Cui JB, Elander RT, Laser M, et al. Fractionating recalcitrant lignocellulose at modest reaction conditions. Biotechnol Bioeng. 2007;97:214-23.

[66] Liu ZH, Chen HZ. Periodic peristalsis enhancing the high solids enzymatic hydrolysis performance of steam exploded corn stover biomass. Biomass Bioenerg. 2016;93:13-24.

[67] Liu ZH, Chen HZ. Periodic peristalsis releasing constrained water in high solids enzymatic hydrolysis of steam exploded corn stover. Bioresour Technol. 2016;205:142-52.

[68] Liu ZH, Chen HZ. Simultaneous saccharification and co-fermentation for improving the xylose utilization of steam exploded corn stover at high solid loading. Bioresour Technol. 2016;201:15-26.

[69] Bondesson PM, Dupuy A, Galbe M, Zacchi G. Optimizing Ethanol and Methane Production from Steam-pretreated, Phosphoric Acid-impregnated Corn Stover. Appl Biochem Biotechnol. 2015; 175:1371-88.

[70] Liu ZH, Chen HZ. Xylose production from corn stover biomass by steam explosion combined with enzymatic digestibility. Bioresour Technol. 2015;193:345-56.

[71] Mo CL, Chen N, Lv T, Du JL, Tian S. Direct Ethanol Production from Steam-Exploded Corn Stover using a Synthetic Diploid Cellulase-displaying Yeast Consortium. BioResources. 2015;10:4460-72.

[72] De Bari I, Cuna D, Di Matteo V, Liuzzi F. Bioethanol production from steam-pretreated corn stover through an isomerase mediated process. New Biotech. 2014;31:185-95.

[73] Liu ZH, Qin L, Zhu JQ, Li BZ, Yuan YJ. Simultaneous saccharification and fermentation of steamexploded corn stover at high glucan loading and high temperature. Biotechnol Biofuels. 2014;7:16782.

[74] Rana V, Eckard AD, Ahring BK. Comparison of SHF and SSF of wet exploded corn stover and loblolly 
pine using in-house enzymes produced from T. reesei RUT C30 and A. saccharolyticus. SpringerPlus. 2014;3:13.

[75] Wang Z, Lv Z, Du J, Mo C, Yang X, Tian S. Combined process for ethanol fermentation at high-solids loading and biogas digestion from unwashed steam-exploded corn stover. Bioresour Technol. 2014;166:282-7.

[76] Bondesson PM, Galbe M, Zacchi G. Ethanol and biogas production after steam pretreatment of corn stover with or without the addition of sulphuric acid. Biotechnol Biofuels. 2013;6:11-21.

[77] Liu ZH, Qin L, Pang F, Jin MJ, Li BZ, Kang Y, et al. Effects of biomass particle size on steam explosion pretreatment performance for improving the enzyme digestibility of corn stover. Ind Crop Prod. 2013;44:176-84.

[78] Pang F, Xue SL, Yu SS, Zhang C, Li B, Kang Y. Effects of combination of steam explosion and microwave irradiation (SE-MI) pretreatment on enzymatic hydrolysis, sugar yields and structural properties of corn stover. Ind Crop Prod. 2013;42:402-8.

[79] Tian S, Li Y, Wang Z, Yang XS. Evaluation of Simultaneous Saccharification and Ethanol Fermentation of Undetoxified Steam-Exploded Corn Stover by Saccharomyces cerevisiae Y5. BioEnergy Res. 2013;6:1142-6.

[80] Yu YL, Feng YJ, Xu C, Liu J, Li DM. Onsite bio-detoxification of steam-exploded corn stover for cellulosic ethanol production. Bioresour Technol. 2011;102:5123-8.

[81] Lu YF, Wang YH, Xu GQ, Chu J, Zhuang YP, Zhang SL. Influence of High Solid Concentration on Enzymatic Hydrolysis and Fermentation of Steam-Exploded Corn Stover Biomass. Appl Biochem Biotechnol. 2010;160:360-9.

[82] Sassner P, Galbe M, Zacchi G. Techno-economic evaluation of bioethanol production from three different lignocellulosic materials. Biomass Bioenerg. 2008;32:422-30.

[83] Cao GL, Ximenes E, Nichols NN, Frazer SE, Kim D, Cotta MA, et al. Bioabatement with hemicellulase supplementation to reduce enzymatic hydrolysis inhibitors. Bioresour Technol. 2015;190:412-5.

[84] Buruiana CT, Vizireanu C, Garrote G, Parajo JC. Optimization of corn stover biorefinery for coproduction of oligomers and second generation bioethanol using non-isothermal autohydrolysis. Ind Crop Prod. 2014;54:32-9.

[85] Li HQ, Jiang W, Jia JX, Xu J. pH pre-corrected liquid hot water pretreatment on corn stover with high hemicellulose recovery and low inhibitors formation. Bioresour Technol. 2014;153:292-9.

[86] Li XZ, Lu J, Zhao J, Qu YB. Characteristics of Corn Stover Pretreated with Liquid Hot Water and FedBatch Semi-Simultaneous Saccharification and Fermentation for Bioethanol Production. PLoS One. 2014;9:1-11.

[87] Lu J, Li XZ, Yang RF, Zhao J, Qu YB. Tween 40 pretreatment of unwashed water-insoluble solids of reed straw and corn stover pretreated with liquid hot water to obtain high concentrations of bioethanol. Biotechnol Biofuels. 2013;6:159-69.

[88] Zeng MJ, Ximenes E, Ladisch MR, Mosier NS, Vermerris W, Huang CP, et al. Tissue-specific biomass recalcitrance in corn stover pretreated with liquid hot-water: Enzymatic hydrolysis (part 1). Biotechnol Bioeng. 2012;109:390-7.

[89] Xu J, Thomsen MH, Thomsen AB. Ethanol production from hydrothermal pretreated corn stover with a loop reactor. Biomass Bioenerg. 2010;34:334-9.

[90] Xu J, Thomsen MH, Thomsen AB. Pretreatment on Corn Stover with Low Concentration of Formic Acid. J Microbiol Biotechnol. 2009; 19:845-50.

[91] Zeng MJ, Mosier NS, Huang CP, Sherman DM, Ladisch MR. Microscopic examination of changes of 
plant cell structure in corn stover due to hot water pretreatment and enzymatic hydrolysis. Biotechnol Bioeng. 2007;97:265-78.

[92] Nghiem NP, Senske GE, Kim TH. Pretreatment of Corn Stover by Low Moisture Anhydrous Ammonia (LMAA) in a Pilot-Scale Reactor and Bioconversion to Fuel Ethanol and Industrial Chemicals. Appl Biochem Biotechnol. 2016;179:111-25.

[93] Sarks C, Bals BD, Wynn J, Teymouri F, Schwegmann S, Sanders K, et al. Scaling up and benchmarking of ethanol production from pelletized pilot scale AFEX treated corn stover using Zymomonas mobilis 8b. Biofuels-UK. 2016;7:253-62.

[94] Sousa LD, Jin MJ, Chundawat SPS, Bokade V, Tang XY, Azarpira A, et al. Next-generation ammonia pretreatment enhances cellulosic biofuel production. Energy Environ Sci. 2016;9:1215-23.

[95] Yoo CG, Kim H, Lu FC, Azarpira A, Pan XJ, Oh KK, et al. Understanding the Physicochemical Characteristics and the Improved Enzymatic Saccharification of Corn Stover Pretreated with Aqueous and Gaseous Ammonia. BioEnergy Res. 2016;9:67-76.

[96] Zhao C, Shao QJ, Ma ZQ, Li B, Zhao XJ. Physical and chemical characterizations of corn stalk resulting from hydrogen peroxide presoaking prior to ammonia fiber expansion pretreatment. Ind Crop Prod. 2016;83:86-93.

[97] Zhao C, Ding WM, Chen F, Cheng C, Shao QJ. Effects of compositional changes of AFEX-treated and H-AFEX-treated corn stover on enzymatic digestibility. Bioresour Technol. 2014;155:34-40.

[98] Zhao C, Shao QJ, Li B, Ding WM. Comparison of Hydrogen Peroxide and Ammonia Pretreatment of Corn Stover: Solid Recovery, Composition Changes, and Enzymatic Hydrolysis. Energy Fuels. 2014;28:6392-7.

[99] Zhu JQ, Qin L, Li BZ, Yuan YJ. Simultaneous saccharification and co-fermentation of aqueous ammonia pretreated corn stover with an engineered Saccharomyces cerevisiae SyBE005. Bioresour Technol. 2014;169:9-18.

[100] Jin MJ, Gunawan C, Balan V, Yu XR, Dale BE. Continuous SSCF of AFEX (TM) pretreated corn stover for enhanced ethanol productivity using commercial enzymes and Saccharomyces cerevisiae 424A (LNH-ST). Biotechnol Bioeng. 2013;110:1302-11.

[101] Qin L, Liu ZH, Jin MJ, Li BZ, Yuan YJ. High temperature aqueous ammonia pretreatment and postwashing enhance the high solids enzymatic hydrolysis of corn stover. Bioresour Technol. 2013;146:504-11.

[102] Zhang C, Pang F, Li B, Xue SL, Kang Y. Recycled aqueous ammonia expansion (RAAE) pretreatment to improve enzymatic digestibility of corn stalks. Bioresour Technol. 2013;138:314-20.

[103] Bals BD, Teymouri F, Campbell T, Jin MJ, Dale BE. Low Temperature and Long Residence Time AFEX Pretreatment of Corn Stover. BioEnergy Res. 2012;5:372-9.

[104] Jin MJ, Gunawan C, Balan V, Lau MW, Dale BE. Simultaneous saccharification and co-fermentation (SSCF) of AFEX (TM) pretreated corn stover for ethanol production using commercial enzymes and Saccharomyces cerevisiae 424A(LNH-ST). Bioresour Technol. 2012;110:587-94.

[105] Jin MJ, Balan V, Gunawan C, Dale BE. Consolidated Bioprocessing (CBP) Performance of Clostridium phytofermentans on AFEX-Treated Corn Stover for Ethanol Production. Biotechnol Bioeng. 2011;108:1290-7.

[106] Li XA, Kim TH. Low-liquid pretreatment of corn stover with aqueous ammonia. Bioresour Technol. 2011;102:4779-86.

[107] Yoo CG, Nghiem NP, Hicks KB, Kim TH. Pretreatment of corn stover using low-moisture anhydrous ammonia (LMAA) process. Bioresour Technol. 2011;102:10028-34.

[108] Li X, Kim TH, Nghiem NP. Bioethanol production from corn stover using aqueous ammonia 
pretreatment and two-phase simultaneous saccharification and fermentation (TPSSF). Bioresour Technol. 2010;101:5910-6.

[109] Lau MW, Dale BE. Cellulosic ethanol production from AFEX-treated corn stover using Saccharomyces cerevisiae 424A(LNH-ST). Proc Natl Acad Sci U S A. 2009;106:1368-73.

[110] Garcia-Torreiro M, Lopez-Abelairas M, Lu-Chau TA, Lema JM. Fungal pretreatment of agricultural residues for bioethanol production. Ind Crop Prod. 2016;89:486-92.

[111] Saha BC, Qureshi N, Kennedy GJ, Cotta MA. Biological pretreatment of corn stover with white-rot fungus for improved enzymatic hydrolysis. Int Biodeterior Biodegrad. 2016;109:29-35.

[112] Song LL, Yu HB, Ma FY, Zhang XY. Biological Pretreatment under Non-sterile Conditions for Enzymatic Hydrolysis of Corn Stover. BioResources. 2013;8:3802-16.

[113] Cui ZF, Wan CX, Shi J, Sykes RW, Li YB. Enzymatic Digestibility of Corn Stover Fractions in Response to Fungal Pretreatment. Ind Eng Chem Res. 2012;51:7153-9.

[114] Gao ZQ, Mori T, Kondo R. The pretreatment of corn stover with Gloeophyllum trabeum KU-41 for enzymatic hydrolysis. Biotechnol Biofuels. 2012;5:28-38.

[115] Sun FH, Li J, Yuan YX, Yan ZY, Liu XF. Effect of biological pretreatment with Trametes hirsuta yj9 on enzymatic hydrolysis of corn stover. Int Biodeterior Biodegrad. 2011;65:931-8.

[116] Wan CX, Li YB. Effectiveness of microbial pretreatment by Ceriporiopsis subvermispora on different biomass feedstocks. Bioresour Technol. 2011;102:7507-12.

[117] Wan CX, Li YB. Microbial delignification of corn stover by Ceriporiopsis subvermispora for improving cellulose digestibility. Enzyme Microb Technol. 2010;47:31-6.

[118] Wan CX, Li YL. Microbial pretreatment of corn stover with Ceriporiopsis subvermispora for enzymatic hydrolysis and ethanol production. Bioresour Technol. 2010;101:6398-403.

[119] Xu CY, Ma FY, Zhang XY, Chen SL. Biological Pretreatment of Corn Stover by Irpex lacteus for Enzymatic Hydrolysis. J Agric Food Chem. 2010;58:10893-8.

[120] Brodeur G, Telotte J, Stickel JJ, Ramakrishnan S. Two-stage dilute-acid and organic-solvent lignocellulosic pretreatment for enhanced bioprocessing. Bioresour Technol. 2016;220:621-8.

[121] Cai LY, Ma YL, Ma XX, Lv JM. Improvement of enzymatic hydrolysis and ethanol production from corn stalk by alkali and N-methylmorpholine-N-oxide pretreatments. Bioresour Technol. 2016;212:42-6.

[122] Chen XW, Kuhn E, Jennings EW, Nelson R, Tao L, Zhang M, et al. DMR (deacetylation and mechanical refining) processing of corn stover achieves high monomeric sugar concentrations $(230 \mathrm{~g}$ L-1) during enzymatic hydrolysis and high ethanol concentrations ( $>10 \% \mathrm{v} / \mathrm{v})$ during fermentation without hydrolysate purification or concentration. Energy Environ Sci. 2016;9:1237-45.

[123] Jiang W, Xu J. A novel stepwise pretreatment on corn stalk by alkali deacetylation and liquid hot water for enhancing enzymatic hydrolysis and energy utilization efficiency. Bioresour Technol. 2016;209:115-24.

[124] Li WZ, Liu QY, Ma QZ, Zhang TW, Ma LL, Jameel H, et al. A two-stage pretreatment process using dilute hydrochloric acid followed by Fenton oxidation to improve sugar recovery from corn stover. Bioresour Technol. 2016;219:753-6.

[125] Liu QY, Li WZ, Ma QZ, An SX, Li MH, Jameel H, et al. Pretreatment of corn stover for sugar production using a two-stage dilute acid followed by wet-milling pretreatment process. Bioresour Technol. 2016;211:435-42.

[126] Lee JW, Kim JY, Jang HM, Lee MW, Park JM. Sequential dilute acid and alkali pretreatment of corn stover: Sugar recovery efficiency and structural characterization. Bioresour Technol. 2015;182:296301. 
[127] Buruiana CT, Vizireanu C, Garrote G, Parajo JC. Bioethanol Production from Hydrothermally Pretreated and Delignified Corn Stover by Fed-Batch Simultaneous Saccharification and Fermentation. Energy Fuels. 2014;28:1158-65.

[128] Mou HY, Li B, Fardim P. Pretreatment of Corn Stover with the Modified Hydrotropic Method To Enhance Enzymatic Hydrolysis. Energy Fuels. 2014;28:4288-93.

[129] Zu S, Li WZ, Zhang MJ, Li ZH, Wang ZY, Jameel H, et al. Pretreatment of corn stover for sugar production using dilute hydrochloric acid followed by lime. Bioresour Technol. 2014;152:364-70.

[130] Tan L, Tang YQ, Nishimura H, Takei S, Morimura S, Kida K. Efficient production of bioethanol from corn stover by pretreatment with a combination of sulfuric acid and sodium hydroxide. Prep Biochem Biotechnol. 2013;43:682-95.

[131] Chen XW, Shekiro J, Elander R, Tucker M. Improved Xylan Hydrolysis of Corn Stover by Deacetylation with High Solids Dilute Acid Pretreatment. Ind Eng Chem Res. 2012;51:70-6.

[132] Zimbardi F, Viola E, Nanna F, Larocca E, Cardinale M, Barisano D. Acid impregnation and steam explosion of corn stover in batch processes. Ind Crop Prod. 2007;26:195-206.

[133] Clavreul J, Baumeister H, Christensen TH, Damgaard A. An environmental assessment system for environmental technologies. Environ Modell Softw. 2014;60:18-30.

[134] Cencic O, Rechberger H. Material flow analysis with Software STAN. Journal of Environmental Engineering and Management. 2008;18:3-7.

[135] Zhang TY, Kumar R, Tsai YD, Elander RT, Wyman CE. Xylose yields and relationship to combined severity for dilute acid post- hydrolysis of xylooligomers from hydrothermal pretreatment of corn stover. Green Chem. 2015;17:394-403.

[136] Saha BC, Qureshi N, Kennedy GJ, Cotta MA. Enhancement of xylose utilization from corn stover by a recombinant Escherichia coli strain for ethanol production. Bioresour Technol. 2015;190:182-8.

[137] Sanny T, Arnaldos M, Kunkel SA, Pagilla KR, Stark BC. Engineering of ethanolic E. coli with the Vitreoscilla hemoglobin gene enhances ethanol production from both glucose and xylose. Appl Microbiol Biotechnol. 2010;88:1103-12.

[138] Mittal A, Vinzant TB, Brunecky R, Black SK, Pilath HM, Himmel ME, et al. Investigation of the role of lignin in biphasic xylan hydrolysis during dilute acid and organosolv pretreatment of corn stover. Green Chem. 2015; 17:1546-58.

[139] Pu YQ, Hu F, Huang F, Ragauskas AJ. Lignin Structural Alterations in Thermochemical Pretreatments with Limited Delignification. BioEnergy Res. 2015;8:992-1003.

[140] Olsen SN, Borch K, Cruys-Bagger N, Westh P. The Role of Product Inhibition as a Yield-Determining Factor in Enzymatic High-Solid Hydrolysis of Pretreated Corn Stover. Appl Biochem Biotechnol. 2014;174:146-55.

[141] Kristensen JB, Felby C, Jorgensen H. Yield-determining factors in high-solids enzymatic hydrolysis of lignocellulose. Biotechnol Biofuels. 2009;2:11-20.

[142] Um BH, van Walsum GP. Effect of Pretreatment Severity on Accumulation of Major Degradation Products from Dilute Acid Pretreated Corn Stover and Subsequent Inhibition of Enzymatic Hydrolysis of Cellulose. Appl Biochem Biotechnol. 2012;168:406-20.

[143] Zhou Y, Li Y, Wan C, Li D, Mao Z. Effect of hot water pretreatment severity on the degradation and enzymatic hydrolysis of corn stover. Trans ASABE. 2010;53:1929-34.

[144] Zhang ZY, Vancov T, Mackintosh S, Basu B, Lali A, Qian GR, et al. Assessing dilute acid pretreatment of different lignocellulosic biomasses for enhanced sugar production. Cellulose. 2016;23:3771-83. 


\section{Captions of figures and tables}

2 Figure 1 Number of annual datasets and publications on corn stover conversion into bioethanol, in total and according to technological configurations

Figure 2 Distribution of datasets per year (2007-2016) according to technological configuration for converting corn stover to bioethanol

Figure 3 Material flows (average with standard deviation) for eight technological configurations of corn stover conversion into ethanol, based on 100 mass units of input dry matter (numbers " $\mathrm{x} / \mathrm{y}$ " in parentheses stand for x available data from y datasets for C6 (glucan/glucose) or C5 (xylan/xylose) in the process)

Figure 4 Ethanol yield in eight technological configurations (S1-S8) for producing ethanol from corn stover relative to the content of a) raw glucan and b) the sum of raw glucan and xylan, respectively (solid circle: median; hollow triangle: average; box: first to third quartile; line: minimum and maximum; asterisk: outlier; dashed line: reference value from USA National Renewable Energy Laboratory [28])

Figure 5 Distribution of the fate of glucan and xylan according to the process step (pretreatment, hydrolysis, fermentation) and technological configuration (S1-S8) (data for S8 not shown, because S8 contains different process step combinations not directly referable to the above graphical presentations)

Figure 6 Distribution of key process parameters according to technological configuration (data for S8 not shown, because S8 contains different process step combinations not directly referable to the above graphical presentations)

Table 1 Parameters identified in the process configurations for bioconversion of corn stover into ethanol

Table 2 Summary of output flows (\%) (average with standard deviation) for eight technological configurations of corn stover bioconversion into ethanol, based on 100 mass units of dry matter in the input

Table 3 Statistical description of the operational parameters in each technological configuration (M: mode; MD: median; A: average; SD: deviation)

Table 4 Performance estimation of probable best technologies, with a top $15 \%$ of yields (\%)

Table 5 Correlation coefficients between key parameters in the pretreatment and hydrolysis processes within all available data (141 datasets) 